\title{
Hearing in adults with Pompe disease
}

\author{
Nadine A. M. E. van der Beek • Hans Verschuure • \\ Arnold J. J. Reuser • Ans T. van der Ploeg • \\ Pieter A. van Doorn • René M. L. Poublon
}

Received: 12 April 2011 /Revised: 28 August 2011 /Accepted: 8 September 2011 / Published online: 15 October 2011

(C) The Author(s) 2011. This article is published with open access at Springerlink.com

\begin{abstract}
Hearing loss has been recognized as an important cause of morbidity in infants with Pompe disease, a metabolic disorder caused by deficiency of acid $\alpha$ glucosidase. It is unknown whether hearing is also affected in adult Pompe patients. We have studied the prevalence, severity, and type of hearing loss in 58 adult patients using tympanometry and pure-tone audiometry. Compared to normative data (International Organisation for Standardisation standard 7029), $72 \%$ of patients had impaired
\end{abstract}

Communicated by: Robin Lachmann

Competing interests: None declared.

N. A. M. E. van der Beek $(\varangle) \cdot$ P. A. van Doorn

Department of Neurology, Center for Lysosomal and Metabolic

Diseases, Erasmus MC University Medical Center,

's-Gravendijkwal 230,

3015 CE Rotterdam, The Netherlands

e-mail: n.beek@erasmusmc.nl

\section{N. A. M. E. van der Beek - A. T. van der Ploeg}

Department of Pediatrics, Center for Lysosomal and Metabolic

Diseases, Erasmus MC University Medical Center - Sophia

Children's Hospital,

Rotterdam, The Netherlands

\section{H. Verschuure}

Department of ENT, Hearing and Speech Center,

Erasmus MC University Medical Center,

Rotterdam, The Netherlands

\section{A. J. J. Reuser}

Department of Clinical Genetics, Center for Lysosomal and Metabolic Diseases, Erasmus MC University Medical Center, Rotterdam, The Netherlands

\section{R. M. L. Poublon}

Department of Otorhinolaryngology-Head and Neck Surgery, Erasmus MC University Medical Center,

Rotterdam, The Netherlands hearing thresholds at one or more frequencies in at least one ear. All measured frequencies were equally affected. All patients had a sensorineural type of hearing loss, pointing to cochlear or retrocochlear pathology. Categorised according to the standards of the World Health Organisation $21 \%$ of patients had a clinically relevant hearing loss (16\% slight, 3\% moderate, $2 \%$ profound). Though this suggests that hearing loss occurs in a considerable number of patients with Pompe disease, this prevalence is similar to that in the general population. Therefore, we conclude that hearing loss is not a specific feature of Pompe disease in adults.

\section{Introduction}

Pompe disease (also called Glycogen Storage Disease type II or acid maltase deficiency) (OMIM 232300) is a lysosomal storage disorder caused by deficiency of the enzyme acid $\alpha$-glucosidase (EC 3.2.1.3). This deficiency results in lysosomal glycogen accumulation, leading to a multi-system disorder affecting virtually all body tissues in patients with the classic infantile phenotype, or to a more slowly progressive disease mainly affecting skeletal and respiratory muscle function in older children and adults (Hirschhorn and Reuser 2001; van der Ploeg and Reuser 2008; Laforêt et al. 2000; Wokke et al. 2008).

Hearing deficits have been reported in several lysosomal storage diseases, including Fabry disease, Gaucher disease and the Mucopolysaccharidoses (Bamiou et al. 2001; Campbell et al. 2003; Hegemann et al. 2006; Keilmann et al. 2009; Komura et al. 1998; Peck 1984; Schachern et al. 1989). In Pompe disease, hearing loss is increasingly recognised as an important cause of morbidity in patients with the classic infantile phenotype. So far, auditory 
function has been described in the literature for 22 classic infantile Pompe patients. Sixteen of these 22 patients had a hearing deficit (Kamphoven et al. 2004; Kishnani et al. 2006; Klinge et al. 2005; Rohrbach et al. 2010; van Capelle et al. 2010a). The observation of glycogen storage in the cells of the organ of Corti in knock-out mice with Pompe disease suggests that cochlear pathology is the main cause of the hearing impairment (Kamphoven et al. 2004). In older children with Pompe disease, hearing problems are sporadically present (van Capelle et al. 2010a). In two related studies on late-onset / adult-onset Pompe disease four patients were mentioned to have hearing impairment, but the problem was not studied systematically, and it is as yet unknown whether hearing impairment occurs more frequently in adults with Pompe disease than in the general population (Müller-Felber et al. 2007; Schoser et al. 2007). It is quite possible that hearing problems develop only after a prolonged period of time in patients who have residual enzyme activity.

Since the introduction of enzyme replacement therapy with alglucosidase alfa (Myozyme ${ }^{\circledR}$, Genzyme Corporation) the perspective of patients with Pompe disease has changed (Chakrapani et al. 2010; Kishnani et al. 2007; Strothotte et al. 2009; van Capelle et al. 2010b; Van den Hout et al. 2001; van der Ploeg et al. 2010; Winkel et al. 2004). Today, the focus is not exclusively on the most limiting aspects of the disease such as reduced mobility and impaired respiration, but it has also shifted towards other aspects that may influence the quality of life. Increased awareness can lead to earlier detection of hearing loss and timely hearing rehabilitation. Therefore, we studied the prevalence, severity, and type of hearing impairment in a cohort of 58 Dutch adults with Pompe disease who are followed in our centre.

\section{Patients and methods}

Patients and procedures

Data were obtained between October 2004 and August 2009 as part of an ongoing nationwide study in the Netherlands on the natural course of Pompe disease. All patients were seen at Erasmus MC University Medical Center. Patients were recruited through neuromuscular centres within the Netherlands, or through the Dutch neuromuscular patient organisation. The study was approved by the Central Committee on Research Involving Human Subjects in the Netherlands (CCMO). All patients provided written informed consent. At the time of the investigation, none of the patients received enzyme replacement therapy.
Hearing assessment

The hearing examination comprised tympanometry and pure-tone audiometry. Pure-tone audiometry was recorded using a Madsen OB822 clinical audiometer (Copenhagen, Denmark) and standard TDH 39 earphones with MX41-AR cushions. Air conduction thresholds and bone conduction thresholds were obtained for each ear at $0.25,0.5,1,2,4$ and $8 \mathrm{kHz}$ according to a standardised protocol (International Organisation for Standardisation (ISO) 8253-1) (International Organisation for Standardisation 1989). All audiometric tests were performed by an experienced audiologist. Hearing thresholds were considered abnormal if they were below the 95th percentile of the predicted value using normative data from the ISO standard 7029 for comparison (International Organisation for Standardisation 2000). Conductive hearing loss was considered to be present in case of an air-bone gap of more than $7.5 \mathrm{~dB}$ averaged over the frequencies 0.5 to $2 \mathrm{kHz}$.

To indicate expected difficulty with conversational speech, the guidelines of the World Health Organisation (WHO) on physical functioning, disability and health were used to grade the severity of the hearing impairment. Hearing loss was defined as a pure-tone average (PTA) of thresholds at $0.5,1,2$ and $4 \mathrm{kHz}$ greater than $25 \mathrm{~dB}$ hearing level. The ears were classified as better-hearing or worsehearing depending on this average score. The severity of hearing loss was categorised as slight $(26-40 \mathrm{~dB})$, moderate $(41-60 \mathrm{~dB})$, severe $(61-80 \mathrm{~dB})$ or profound $(>81 \mathrm{~dB})$ based on this pure-tone average (World Health Organisation 2001).

\section{Additional clinical information}

The following information was available: age at symptom onset, age at diagnosis of Pompe disease, disease duration, use of walking devices or wheelchair, use of ventilatory support, and type of mutation. The presence of contributing medical, genetic or environmental conditions such as noise exposure, exposure to chemicals, or use of ototoxic medication was evaluated by means of a self-reported questionnaire.

Statistical analysis

Continuous variables are presented using mean, median, standard deviation or range. For categorical variables percentages or frequencies are given. Differences in contributing factors between the groups of patients with and without hearing impairment were tested by $\chi^{2}$ analyses. Analyses were performed with SPSS for windows (version 15.0, SPSS Inc., Chicago, IL). A p-value of $\leq 0.05$ was considered significant. 


\section{Results}

Study population

Fifty-eight adults with Pompe disease (29 males, 29 females) were included in the study. The mean age at the time of investigation was 50.5 years (SD 12.5, range 2676 years). The mean age at which first neuromuscular symptoms had manifested, considered as disease onset, was 31.7 years (SD 11.1), and the mean age at diagnosis was 40.7 years (SD 12.8). Disease duration at the time of the investigation ranged from 1 to 48 years (median 18.9 years). Six patients had experienced their first symptoms in childhood or adolescence, at the ages of $1,10,11,15,16$, or 18 years, of whom only the patient who had symptoms in the first year of life had been diagnosed before adulthood. At the time of the hearing investigation, this patient, now 29 years of age, has only mild skeletal muscle weakness and does not need ventilatory support. Eight patients (14\%) used walking devices, 21 (36\%) were wheelchair dependent, and 18 (31\%) used mechanical ventilatory support. Three patients $(5 \%)$ had hearing aids. Fifty-seven patients had the common c.-32-13 T > G (IVS1-13 T > G; leaky splice) mutation, combined with a second pathogenic mutation on the other allele. One patient had genotype c.671 G > A / c.525del (p.Arg224Gln / p. Glu176fsX45).

Hearing assessment by pure-tone audiometry and tympanometry

Sixteen of the 58 patients (28\%) had normal hearing levels for both ears at all frequencies, as measured by pure-tone audiometry. We found abnormal hearing levels in 42 patients (72\%): 22 patients had abnormal hearing thresholds in both ears, and 20 patients in one ear. All measured frequencies were equally affected $(p=0.63)$. Figure $1 \mathrm{a}$ and $\mathrm{b}$ show the hearing thresholds at all frequencies for the individual patients compared to the normative values for age, stratified by gender.

With regard to functional hearing impairment, as assessed by means of self-reported questionnaires, one of the 16 patients with normal hearing thresholds reported difficulty hearing. Of the 42 patients with abnormal hearing thresholds, 14 reported hearing difficulties.

Tympanometry was abnormal in 20 patients (34\%): nine had slightly negative middle ear pressures, 11 had abnormal static admittance. However, a significant contribution (airbone gap of more than $7.5 \mathrm{~dB}$ averaged over the frequencies 0.5 to $2 \mathrm{kHz}$ ) of these conductive abnormalities to the total amount of hearing impairment was present in three patients only: one patient had a perforated eardrum, one had otitis media, and the other one had stiffening of the bony middle-ear structures. The other 39 patients (93\%) had a pure sensorineural type of hearing impairment.

Grading of hearing impairment according to the WHO guidelines

Since abnormalities at one or two of the measured frequencies might not be of clinical importance to the patient, we also graded the hearing impairment according to the WHO guidelines, which better reflects the severity of the hearing loss (Table 1). Regarding the better-hearing ear of each patient, 12 of the 58 patients (21\%) had hearing loss: $16 \%$ of these patients had slight hearing loss, $3 \%$ moderate hearing loss, and $2 \%$ profound hearing loss. Each of these 12 patients had bilateral hearing loss. Based on assessments of the worse-hearing ear, 20 of the 58 patients had some level of hearing loss (34\%). Among these 20 patients are the 12 patients with bilateral hearing loss and an additional eight patients with unilateral hearing loss. For comparison, Table 1 also shows the frequency of hearing loss in the general population, as graded according to the WHO guidelines, stratified by age.

\section{Contributing factors}

Twenty of the 42 patients with abnormal hearing thresholds reported medical, genetic or environmental conditions that may have contributed to the degree of their hearing abnormality. Reported were: noise exposure (eight patients), frequent middle ear infections during childhood (seven patients), familial occurrence of hearing loss (six patients), use of intravenous aminoglycoside antibiotics (five patients), diabetes mellitus (two patients), and use of acetylsalicylic acid (two patients). The proportion of patients reporting possible contributing factors did not differ between the group of patients with abnormal hearing thresholds and the group of patients with normal hearing thresholds $(\mathrm{p}=0.70)$.

\section{Discussion}

We studied the prevalence, severity, and type of hearing loss in adults with Pompe disease to see whether it is an important cause of morbidity in adults, as it is in infants with Pompe disease.

With regard to the prevalence of hearing loss, we found that abnormal hearing thresholds were frequently present among adults with Pompe disease, but that a clinically relevant hearing loss was present in $21 \%$ of patients only. 

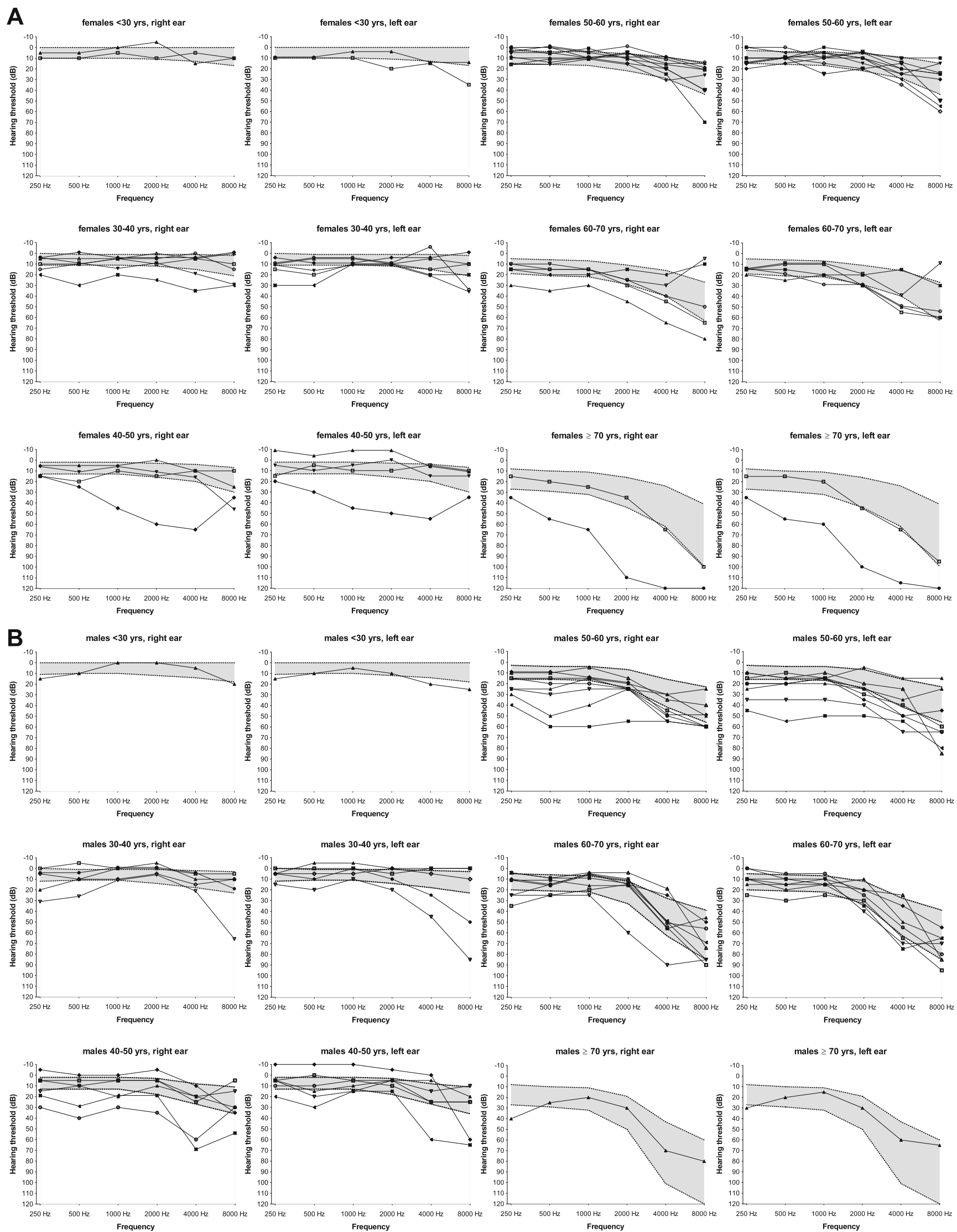
4Fig. 1 Hearing thresholds in 29 females (a) and 29 males (b) with Pompe disease stratified by age. The shaded area represents the 95 percent confidence interval for normal hearing (ISO 7029). The connected lines represent the pure-tone audiograms of the individual patients for the right and left ear; each patient within an age group is represented by a different symbol $(\times, \Delta, \boldsymbol{\Lambda}, \nabla, \nabla, \bullet, \diamond, \bullet, \circ, \mathbf{\square}$, or $\square)$

This percentage seems high, but it appears comparable to the prevalence in the general population, matched for age and gender (Davis 1989; Johansson and Arlinger 2003; Wilson et al. 1999). The severity of hearing loss was categorised as slight in $16 \%$, moderate in $3 \%$, and profound in $2 \%$. Fifty percent of the patients with abnormal hearing thresholds, reported factors such as concomitant disease, noise exposure or use of ototoxic medication, which may be responsible for a certain degree of hearing loss. Unfortunately, it could not be determined to what extent these factors contributed to the observed hearing impairment. Of the patients with normal hearing, the same proportion reported exposure to these conditions.

In all patients in whom we observed hearing loss, we found a sensorineural type of hearing impairment. Only three patients (7\%) also had significant conductive abnormalities, despite the fact that one third of patients had slightly impaired middle ear function. Therefore, the impact of middle ear dysfunction on the overall severity of hearing loss is presumably small.

Hearing loss in Pompe disease was first recognised in patients with the classic infantile phenotype, when it became evident that these patients could survive beyond the age of one year, if they were treated with recombinant human acid $\alpha$-glucosidase (Amalfitano et al. 2001; Kishnani et al. 2007; Van den Hout et al. 2001). Information on the precise cause of the hearing loss in Pompe disease is scarce. One study showed raised auditory brainstem response thresholds in nine of 11 infantile patients, whereas mild abnormalities in inter-peak latency times were seen in five (van Capelle et al. 2010a). Another study reported on flat oto-acoustic emission (OAE) and abnormal wave latencies in brainstem auditory evoked response (BAER) in some infants, pointing to inner ear or auditory nervous system pathology or to both (Kishnani et al. 2006). A study in knock-out mice with Pompe disease led to the discovery of glycogen deposition in the inner hair cells and the outer hair cells of the cochlea, the supporting cells, the stria vascularis, and the spiral ganglion cells (Kamphoven et al. 2004). These findings suggest that cochlear pathology rather than involvement of the central auditory nervous system could be the main cause of the hearing loss. In the present study, we did not investigate auditory brainstem responses. However, since the underlying metabolic defect in adults and infants is the same, the presence of retrocochlear pathology as the primary cause of the hearing impairment in adults with Pompe disease is less likely. The observation that profound hearing

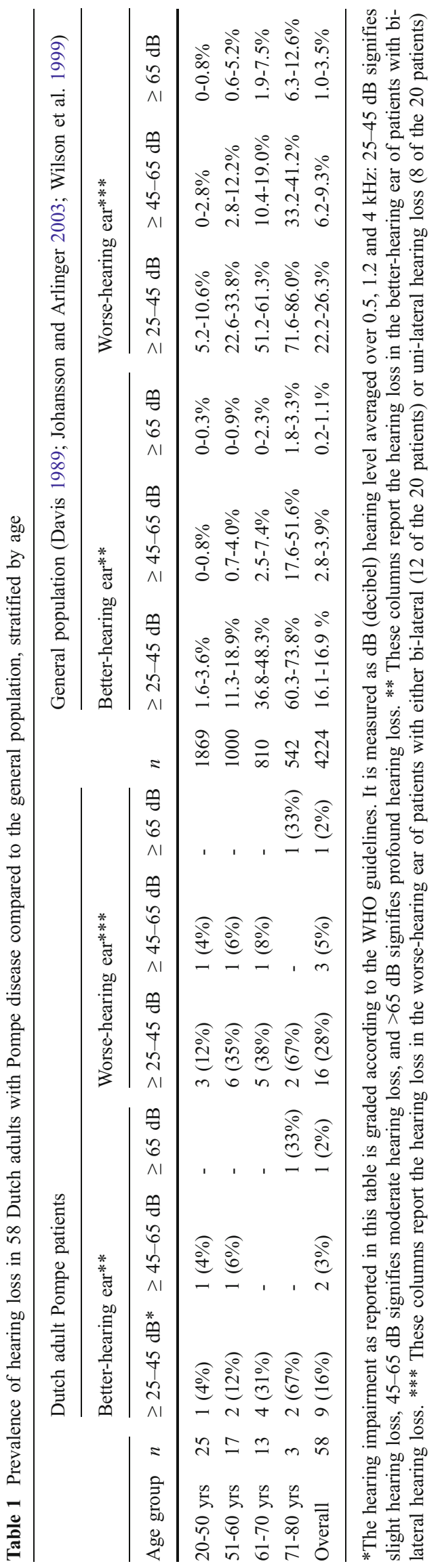


impairment is present in nearly every patient with classic infantile Pompe disease, but only sporadically in older children and adults is probably due to the higher amount of residual $\alpha$-glucosidase activity in the latter groups of patients, preventing generalised glycogen storage.

Due to the development of innovative therapeutic measures and higher standard of care, the perspective of patients with Pompe disease has changed over the last years (Strothotte et al. 2009; van der Ploeg et al. 2010). It is to be expected that the focus will not exclusively be on the most threatening aspects of the disease such as severe muscle weakness and respiratory failure, but will shift towards other aspects that influence the quality of life of patients with Pompe disease. In light of these changing perspectives it is important to conclude that, unlike in infants, clinically relevant hearing loss is not a hallmark of Pompe disease in adults. Therefore, standard screening for hearing impairment does not seem indicative in adult-onset Pompe disease.

Acknowledgements The authors thank all patients for their participation in the study.

Details of funding The research on Pompe disease at Erasmus MC is financially supported by the Erasmus MC Revolving Fund [project number 1054, NAMEvdB]; ZonMw- Netherlands Organisation for Health Research and Development [project no. 152001005]; the Dutch TI Pharma initiative "Sustainable Orphan Drug Development through Registries and Monitoring (T6-208); European Union, 7th Framework Programme "EUCLYD-a European Consortium for Lysosomal Storage Diseases" [health F2/2008 grant agreement 201678]; and the Prinses Beatrix Fonds [project number OP07-08].

The content of the article has not been influenced by the sponsors.

Open Access This article is distributed under the terms of the Creative Commons Attribution Noncommercial License which permits any noncommercial use, distribution, and reproduction in any medium, provided the original author(s) and source are credited.

\section{References}

Amalfitano A, Bengur AR, Morse RP et al. (2001) Recombinant human acid alpha-glucosidase enzyme therapy for infantile glycogen storage disease type II: results of a phase I/II clinical trial. Genet Med 3:132-138

Bamiou DE, Campbell P, Liasis A et al. (2001) Audiometric abnormalities in children with Gaucher disease type 3. Neuropediatrics 32:136-141

Campbell PE, Harris CM, Harris CM, Sirimanna T, Vellodi A (2003) A model of neuronopathic Gaucher disease. J Inherit Metab Dis 26:629-639

Chakrapani A, Vellodi A, Robinson P, Jones S, Wraith JE (2010) Treatment of infantile Pompe disease with alglucosidase alpha: the UK experience. J Inherit Metab Dis 33:747-750

Davis AC (1989) The prevalence of hearing impairment and reported hearing disability among adults in Great Britain. Int J Epidemiol 18:911-917
Hegemann S, Hajioff D, Conti G et al. (2006) Hearing loss in Fabry disease: data from the Fabry Outcome Survey. Eur J Clin Invest 36:654-662

Hirschhorn R, Reuser A (2001) Glycogen storage disease type II: acid aglucosidase (acid maltase) deficiency. In: Scriver CR, Beaudet AL, Sly W, Valle D (eds) The metabolic and molecular bases of inherited disease. McGraw-Hill, New York, pp 3389-3420

International Organization for Standardization (1989) Acoustics Audiometric test methods - Part 1: Basic pure tone air and bone conduction threshold audiometry. ISO 8253-1

International Organization for Standardization (2000) Acoustics statistical distribution of hearing thresholds as a function of age, ISO 7029

Johansson MS, Arlinger SD (2003) Prevalence of hearing impairment in a population in Sweden. Int J Audiol 42:18-28

Kamphoven JH, de Ruiter MM, Winkel LP et al. (2004) Hearing loss in infantile Pompe's disease and determination of underlying pathology in the knockout mouse. Neurobiol Dis 16:14-20

Keilmann A, Hajioff D, Ramaswami U (2009) Ear symptoms in children with Fabry disease: data from the Fabry Outcome Survey. J Inherit Metab Dis 32:739-744

Kishnani PS, Nicolino M, Voit T et al. (2006) Chinese hamster ovary cell-derived recombinant human acid alpha-glucosidase in infantile-onset Pompe disease. J Pediatr 149:89-97

Kishnani PS, Corzo D, Nicolino M et al. (2007) Recombinant human acid [alpha]-glucosidase: major clinical benefits in infantile-onset Pompe disease. Neurology 68:99-109

Klinge L, Straub V, Neudorf U, Voit T (2005) Enzyme replacement therapy in classical infantile pompe disease: results of a ten-month follow-up study. Neuropediatrics 36:6-11

Komura Y, Kaga K, Ogawa Y, Yamaguchi Y, Tsuzuku T, Suzuki JI (1998) ABR and temporal bone pathology in Hurler's disease. Int J Pediatr Otorhinolaryngol 43:179-188

Laforêt P, Nicolino M, Eymard B et al. (2000) Juvenile and adultonset acid maltase deficiency in France. Genotype-phenotype correlation. Neurology 55:1122-1128

Müller-Felber W, Horvath R, Gempel K et al. (2007) Late onset Pompe disease: clinical and neurophysiological spectrum of 38 patients including long-term follow-up in 18 patients. Neuromuscul Disord 17:698-706

Peck JE (1984) Hearing loss in Hunter's syndrome-mucopolysaccharidosis II. Ear Hear 5:243-246

Rohrbach M, Klein A, Kohli-Wiesner A et al. (2010) CRIM-negative infantile Pompe disease: 42-month treatment outcome. J Inherit Metab Dis 33:751-757

Schachern PA, Shea DA, Paparella MM, Yoon TH (1989) Otologic histopathology of Fabry's disease. Ann Otol Rhinol Laryngol 98:359-363

Schoser BG, Muller-Hocker J, Horvath R et al. (2007) Adult-onset glycogen storage disease type 2: clinico-pathological phenotype revisited. Neuropathol Appl Neurobiol 33:544-559

Strothotte S, Strigl-Pill N, Grunert B et al. (2009) Enzyme replacement therapy with alglucosidase alfa in 44 patients with late-onset glycogen storage disease type 2: 12-month results of an observational clinical trial. J Neurol

van Capelle CI, Goedegebure A, Homans NC, Hoeve HL, Reuser AJ, van der Ploeg AT (2010a) Hearing loss in Pompe disease revisited: results from a study of 24 children. J Inherit Metab Dis 33:597-602

van Capelle CI, van der Beek NA, Hagemans ML et al. (2010b) Effect of enzyme therapy in juvenile patients with Pompe disease: a three-year open-label study. Neuromuscul Disord 20:775-782

van den Hout JM, Reuser AJ, de Klerk JB, Arts WF, Smeitink JA, van der Ploeg AT (2001) Enzyme therapy for pompe disease with recombinant human alpha-glucosidase from rabbit milk. J Inherit Metab Dis 24:266-274 
van der Ploeg AT, Reuser AJ (2008) Pompe's disease. Lancet 372:1342-1353

van der Ploeg AT, Clemens PR, Corzo D et al. (2010) A randomized study of alglucosidase alfa in late-onset Pompe's disease. N Engl J Med 362:1396-1406

Wilson DH, Walsh PG, Sanchez L et al. (1999) The epidemiology of hearing impairment in an Australian adult population. Int $\mathbf{J}$ Epidemiol 28:247-252
Winkel LP, Van den Hout JM, Kamphoven JH et al. (2004) Enzyme replacement therapy in late-onset Pompe's disease: a three-year follow-up. Ann Neurol 55:495-502

Wokke JHJ, Escolar DM, Pestronk A et al. (2008) Clinical features of late-onset Pompe disease: a prospective cohort study. Muscle Nerve 38:1236-1245

World Health Organization (2001) International classification of functioning, disability and health. WHO, Geneva 